\title{
Animal behavior, cost-based corridor models, and real corridors
}

\author{
Scott LaPoint $\cdot$ Paul Gallery $\cdot$ Martin Wikelski • \\ Roland Kays
}

Received: 30 August 2012/ Accepted: 10 June 2013/Published online: 26 June 2013

(C) The Author(s) 2013. This article is published with open access at Springerlink.com

\begin{abstract}
Corridors are popular conservation tools because they are thought to allow animals to safely move between habitat fragments, thereby maintaining landscape connectivity. Nonetheless, few studies show that mammals actually use corridors as predicted. Further, the assumptions underlying corridor models are rarely validated with field data. We categorized corridor use as a behavior, to identify animal-defined corridors, using movement data from fishers (Martes pennanti) tracked near Albany, New York, USA. We then used least-cost path analysis and circuit theory to predict fisher corridors and validated the performance of
\end{abstract}

S. LaPoint $(\bowtie) \cdot$ M. Wikelski

Max-Planck-Institute for Ornithology, Am Obstberg 1, 78315 Radolfzell, Germany

e-mail: sdlapoint@gmail.com

S. LaPoint · M. Wikelski

Department of Biology, University of Konstanz,

Universitätsstraße 10, 78464 Konstanz, Germany

P. Gallery

New York State Museum, 3140 CEC, Albany, NY 12230, USA

R. Kays

North Carolina Museum of Natural Sciences,

11 West Jones Street, Raleigh, NC 27601, USA

R. Kays

Department of Forestry and Environmental Resources, North Carolina State University, Box 8008, Raleigh,

NC 27695, USA all three corridor models with data from camera traps. Six of eight fishers tracked used corridors to connect the forest patches that constitute their home ranges, however the locations of these corridors were not well predicted by the two cost-based models, which together identified only 5 of the 23 used corridors. Further, camera trap data suggest the cost-based corridor models performed poorly, often detecting fewer fishers and mammals than nearby habitat cores, whereas camera traps within animal-defined corridors recorded more passes made by fishers, carnivores, and all other nontarget mammal groups. Our results suggest that (1) fishers use corridors to connect disjunct habitat fragments, (2) animal movement data can be used to identify corridors at local scales, (3) camera traps are useful tools for testing corridor model predictions, and (4) that corridor models can be improved by incorporating animal behavior data. Given the conservation importance and monetary costs of corridors, improving and validating corridor model predictions is vital.

Keywords Animal movement - Carnivore - Circuit theory - Connectivity · Conservation - Fisher .

Least-cost path $\cdot$ Martes pennanti

\section{Introduction}

Conservation corridors are widely regarded as useful tools for improving landscape connectivity because they are thought to facilitate animal movement 
between otherwise separate but potentially suitable habitats (Simpson 1940; Forman 1995; Rosenberg et al. 1997; Gilbert-Norton et al. 2010). Corridors are thought to facilitate dispersal (Haas 1995), maintain gene flow between populations (Mech and Hallett 2001) and, ultimately, reduce extinction risk (Brown and Kodric-Brown 1977). Surprisingly, few data show that mammals move between habitat patches via predicted corridors, perhaps prompting some ecologists to question their effectiveness and value (Simberloff et al. 1992; Hodgson et al. 2009). Given the conservation potential for wildlife corridors and the monetary costs required to implement them, both accuracy in corridor identification and appropriate methods for measuring their utility are needed (Chetkiewicz et al. 2006; Beier et al. 2008; Spear et al. 2010; Sawyer et al. 2011; Zeller et al. 2012).

Typical methods to identify corridors only indirectly consider the animal movements they are designed to facilitate (Chetkiewicz et al. 2006; Beier et al. 2008). Often, experts visually identify potential corridors (Hilty et al. 2006). More sophisticated methods such as cost-based models (e.g., least-cost mapping; Adriaensen et al. 2003 and circuit theory; McRae et al. 2008) use algorithms to analyze landscape resistance to predict corridors. This landscape resistance, or 'cost', is thought to represent the energy or mortality risk for an animal to move through an area, or its unwillingness to do so. Landscape resistance is often based on habitat suitability indices or expert opinion, where high habitat suitability is interpreted as low resistance or cost (Sawyer et al. 2011; Poor et al. 2012; Zeller et al. 2012). Unfortunately, many examples of cost-based corridor model applications have weaknesses, for example the use of habitat selection information that is generalized from the literature (e.g., LaRue and Nielsen 2008; Li et al. 2010; Huck et al. 2011) (despite being locality specific and often variable across sites and thus not generalizable; Fahrig 2007) and the cost-based models themselves unrealistically assume an animal either has complete knowledge of the landscape (e.g., least cost path analysis; Adriaensen et al. 2003) or no memory of the landscape (i.e., random walkers; e.g., McRae et al. 2008). Most importantly, despite intending to predict and facilitate animal movements, most corridor studies do not directly incorporate animal behavior into their models (Chetkiewicz et al. 2006; Beier et al. 2008; Sawyer et al. 2011; Zeller et al.
2012), and only a few have compared their model predictions with movement data (Driezen et al. 2007; Poor et al. 2012; Walpole et al. 2012).

Fortunately, animal movement data are increasingly available to both test predicted corridors and to improve the corridor models themselves (Wikelski et al. 2007; Wikelski and Kays 2012). These new data are part of the emerging field of Movement Ecology (Nathan et al. 2009), that also includes new analytical tools for identifying behaviors of free-ranging animals (Nathan et al. 2012) and for discerning animal behavior using movement data-based models (Fauchald and Tverra 2003; Morales et al. 2004; Jonsen et al. 2005; Gurarie et al. 2009; Kranstauber et al. 2012). These movement models, coupled with improved spatial and temporal resolution of GPS-derived movement data (Brown et al. 2012), are improving our understanding of the mechanistic links between animal behavior, animal space use, and survival in dynamic environments (Morales et al. 2010; Smouse et al. 2010; Bartoń et al. 2012; Buchmann et al. 2012).

In this paper we take a movement ecological approach to delineate functional corridors and test corridor model predictions. First, we developed the "animal-defined corridor" model using high resolution GPS tracking data from fishers (Martes pennanti) to determine whether fishers use corridors to move between the habitat patches within their home ranges in a fragmented, suburban environment. We then used these same tracking data to build the resistance layers for two popular cost-based corridor models: least-cost path analysis (Adriaensen et al. 2003) and circuit theory (i.e., Circuitscape; McRae et al. 2008) to predict the observed fisher corridors. Finally, we evaluated the performance of the animal-defined corridor model and tested the predictions of least-cost path analysis and circuit theory using an independent set of camera trap detection data.

\section{Methods}

Study species and area

Fishers are medium-sized (females $2.0-2.5 \mathrm{~kg}$; males $3.5-5.5 \mathrm{~kg}$ ) carnivores native to the northern forests of North America. Fisher populations suffered dramatic declines following the Euro-American colonization of North America due to over-harvesting, habitat loss and 
habitat fragmentation (Powell 1993). Their range is still restricted along the western coast of the United States but they are expanding out from refugia in much of their eastern range (Lewis et al. 2012). We tracked fishers in suburban forest patches near Albany, New York, USA $(42.765 \mathrm{~N},-73.881 \mathrm{E})$, a relatively flat ( $<100 \mathrm{~m}$ change in elevation) $350 \mathrm{~km}^{2}$ matrix of residential and commercial land uses, interspersed with mixed and northern deciduous forest patches. The road density in this area is $4.77 \mathrm{~km} / \mathrm{km}^{2}$ (New York State Office of Cyber Security 2006) with a human population density of 438 persons $/ \mathrm{km}^{2}$ (US Census United States Census 2008). Our main study area was highly fragmented by roads and development to where six of our eight fishers had home ranges (dynamic Brownian bridge movement model utilization distribution; Kranstauber et al. 2012) that included multiple disjunct habitat patches (i.e., forest patches separated by roads, unsuitable land cover, or other anthropogenic structures) that individuals regularly moved between. One study animal was tracked in nearby (30 km) Grafton Lakes State Park $\left(9.5 \mathrm{~km}^{2}\right)$ a mostly contiguous forested landscape dominated by deciduous and coniferous tree species, with recreation trails and a few gravel roads.

\section{Movement data}

We live-trapped fishers with covered cage traps, sedated them with a combination of ketamine hydrochloride (concentration $=200 \mathrm{mg} / \mathrm{mL}$, dosage $=$ $0.2 \mathrm{~mL} / \mathrm{kg}$ ) and xylazine hydrochloride (concentration $=300 \mathrm{mg} / \mathrm{mL}$, dosage $=0.01 \mathrm{~mL} / \mathrm{kg}$ ), monitored their vital rates, and fitted them with tracking collars (E-obs GmbH; Grünwald, Germany) during the winters of 2009, 2010, and 2011. Collars contained a GPS microchip, an ultra-high frequency radio transmitter, and a tri-axial accelerometer. Prior to deployment, we estimated the location error of the GPS to be $22 \mathrm{~m}$ (mean) via stationary field tests (18 collars, 2,071 locations). The GPS was programmed with a fixed schedule of 10 or 15 min intervals, or a dynamic fix schedule, $24 \mathrm{~h}$ per day. With the dynamic fix schedule, the GPS attempted more frequent locations ( $\geq 2 \mathrm{~min}$ ) when a fisher moved quickly and attempted fewer fixes (every $60 \mathrm{~min}$ ) when the fisher rested (see Brown et al. 2012 for details). Capture and handling protocols were approved by the Institutional Animal
Care and Use Committee at the Max-Planck-Institute for Ornithology.

Cost-based corridor mapping

Cost-based approaches to corridor mapping require assigning resistance values to the landscape variables. These values should represent the cumulative costs (e.g., energetic expenditure, mortality risk, or habitat avoidance) experienced by an individual moving through the landscape (Adriaensen et al. 2003). As our intention here is to test popular cost-based corridor methods, we estimated landscape resistance values from a habitat selection analysis to replicate many of the published cost-based corridor studies (Sawyer et al. 2011). Since fishers are well documented forest specialists (Powell 1993; Lofroth et al. 2011) and roadways are significant barriers to animal movement (Forman et al. 2003), our landscape variables included land cover (30 m resolution, 15 land cover categories; 2006 National Land Cover Dataset; Fry et al. 2011) and a road polyline layer with 7 speed categories that we rasterized to a $30 \mathrm{~m}$ resolution grid (New York State Office of Cyber Security 2006). Despite the influence of topography on resistance estimates, we ignored topography in our analyses as our study area experiences little change $(<100 \mathrm{~m})$ in elevation.

We conducted a weighted compositional analysis for fisher habitat selection (Aebischer et al. 1993; Millspaugh et al. 2006) at the home range scale (i.e., Johnson's (1980) third order of selection), per individual. We used the GPS tracking locations to estimate the 'use' of each land cover type per fisher, and used a dynamic Brownian bridge home range utilization distribution (Kranstauber et al. 2012) to estimate the 'availability' of each land cover type, per fisher. As recommended by Aebischer et al. (1993), for each fisher, if a land cover type was not used by the animal, but was available (i.e., available value was greater than zero), we replaced the unused land cover type use proportion value with a value equal to $10 \%$ of the least available land cover type proportion. We assigned a movement cost to each land cover type (per fisher) by calculating a ranking matrix of the pairwise differences of the natural log-ratios of the use to available proportions (Aebischer et al. 1993). A pairwise difference value of zero indicates random use, whereas negative values suggest the fisher avoided the land cover type and positive values 
suggest the fisher selected for the land cover type. These values are the basis for Aebischer et al.'s (1993) habitat rankings. We then calculated the mean of the pairwise differences per land cover type. We then standardized these pairwise difference means by first subtracting the highest mean value for a land cover type (per individual) from each land cover type value and then we divided these standardized values by the lowest standardized value to make each land cover type relative to the least selected for (i.e., most costly). As both least-cost path analysis and Circuitscape require cost values $\geq 1$, we assigned the least costly land cover types a value of 1 (previously 0 ) and then multiplied the remaining values by 100 . The final values range from 1 (least costly) to 100 (most costly).

Both least-cost path analysis and Circuitscape require source and destination points or areas (Adriaensen et al. 2003; McRae et al. 2008), for which we used fisher rest sites. Our fishers were highly nocturnal, typically resting at a single site throughout the day (LaPoint unpublished data). We identified these rest sites as GPS location clusters where a fisher spent $>4$ daytime hours during which they were minimally active, as indicated by low variability in accelerometer measures (see Brown et al. 2012). An alternative to using rest sites would have been to model corridors between habitat or home range cores. Doing so, however, requires a priori distinguishing between habitat, periphery, and core areas, which can vary depending on the home range estimator used (Cumming and Cornélis 2012) and can be confounded when numerous locations are recorded within frequently used corridors. Rest sites offer a simple alternative as they were numerous and well distributed across each fishers home range, they can easily be identified with animal tracking data and field investigations, and their definition is stable and straightforward across studies (Powell 1994; Kilpatrick and Rego 1994; Lofroth et al. 2011).

For each fisher separately, we predicted the locations of corridors between its rest sites with least-cost path analysis and circuit theory using the cost values from the habitat selection information for the fisher. We conducted least-cost path analysis using the Spatial Analyst toolbox within ArcMap (version 9.3 build 1770; ESRI 2008). We modeled least-cost paths between all possible combinations of rest sites, per individual. We identified possible corridors from least-cost path analysis as cells whose least-cost path density is $\geq 2$, i.e., at least two least-cost paths overlapped within the cell, and required that these overlapping paths were each traveling in opposite directions (i.e., the path connecting a 'source' rest site to a 'destination' rest site was overlapped by another path when the designations of these rest sites was reversed). We chose least-cost path analysis over the similar least-cost corridor method (Sawyer et al. 2011) to avoid subjective accumulative cost thresholds and to force a path to/from the most isolated rest sites that least-cost corridor analysis may have determined too costly to reach (i.e., above the accumulative cost threshold). Next, for each fisher, we used the same cost layers to generate cumulative current outputs from Circuitscape (version 3.5.4; www.circuitscape.org), to predict fisher corridors between each rest site (i.e., focal nodes). Each current map is a raster with continuous grid cell values of current flow, where current values are indicative of predicted movement of random walkers. These maps are useful tools for visualizing movement bottlenecks, barriers, and connectivity across landscapes, but can be difficult to objectively interpret (Rudnick et al. 2012). We are unaware of a quantitative and objective method for delineating corridors via current maps, therefore we identified potential corridors visually from current maps, where relatively high current levels suggested funneled fisher movements. In summary, for both the least-cost path analysis and circuit theory approaches, we predicted corridors for each fisher using the same data inputs for both approaches (i.e., conducted on each fisher separately, using the same cost layers per animal, and the same source and destination points). However, the algorithms used by each approach to predict corridors from the cost layers differ. In leastcost path analysis, the cost distance (i.e., the Euclidian distance weighted by the cumulative cost of each cell traversed) is estimated between a source and a destination, from which the least costly path represents the connected cells whose summed cost-weighted distance is the lowest (Adriaensen et al. 2003). Whereas circuit theory algorithms generate random walks originating from designated source points, with each landscape grid cell's value representing the number of walkers that reached the cell divided by the resistance of the cell. In electrical circuit theory this translates as current or the voltage (the amount of walkers) divided by the resistance (cost), thus a current cell value can indicate either low resistance or high voltage, or both. 
Finally, due to the outputs for each cost model, our interpretation of each approach's results had to differ slightly since least-cost path corridors were objectively identified via overlapping paths and circuit theory corridors were identified subjectively, but with careful visual inspection of quantitative current maps. Both of these approaches are popular and current practices (Rudnick et al. 2012).

Identifying animal-defined corridors

We analyzed our high-resolution fisher tracking data to determine if fishers used corridors within their home ranges. We considered corridor use as efficient and repeated movement between two or more habitat patches within a home range (Hobbs 1992; Rosenberg et al. 1997; Hilty et al. 2006). The efficiency of movement distinguishes corridors from otherwise linear foraging habitats since corridors should primarily be used for traveling (Forman 1995; Rosenberg et al. 1997). For this analysis we interpret rapid movements as efficient movement, and define corridors as areas characterized by parallel, quick and repeated animal movement paths. We refer to these areas as animal-defined corridors. We believe our corridor definition is similar to previously used definitions. However, our definition may more explicitly incorporate corridor function (quick and repeated movements) and corridor form (parallel movements) than previously used definitions. Our method, described below, is available as the corridor function within the package 'move' (version 1.1; Kranstauber and Smolla 2013) for program R (version 2.15.2; R Development Core Team 2012).

We first estimated the speed and the variation in the direction traveled by an animal to define potential corridor movement behaviors empirically. For each individual we divided the entire movement path into steps representing the estimated path between successive locations, with the midpoint of each step being assigned the speed $(\mathrm{m} / \mathrm{min})$ and azimuth $\left(-180^{\circ} \leq\right.$ azimuth $\left.<180^{\circ}\right)$ of the fisher moving from the previous location to the next. We identified fast movement steps as those with speeds greater than $75 \%$ of all speeds per animal (Fig. 1a). We created a circular buffer whose radius equals one-half the
Fig. 1 Schematic and description of the animaldefined corridor model using the observed track of an adult male fisher as an example

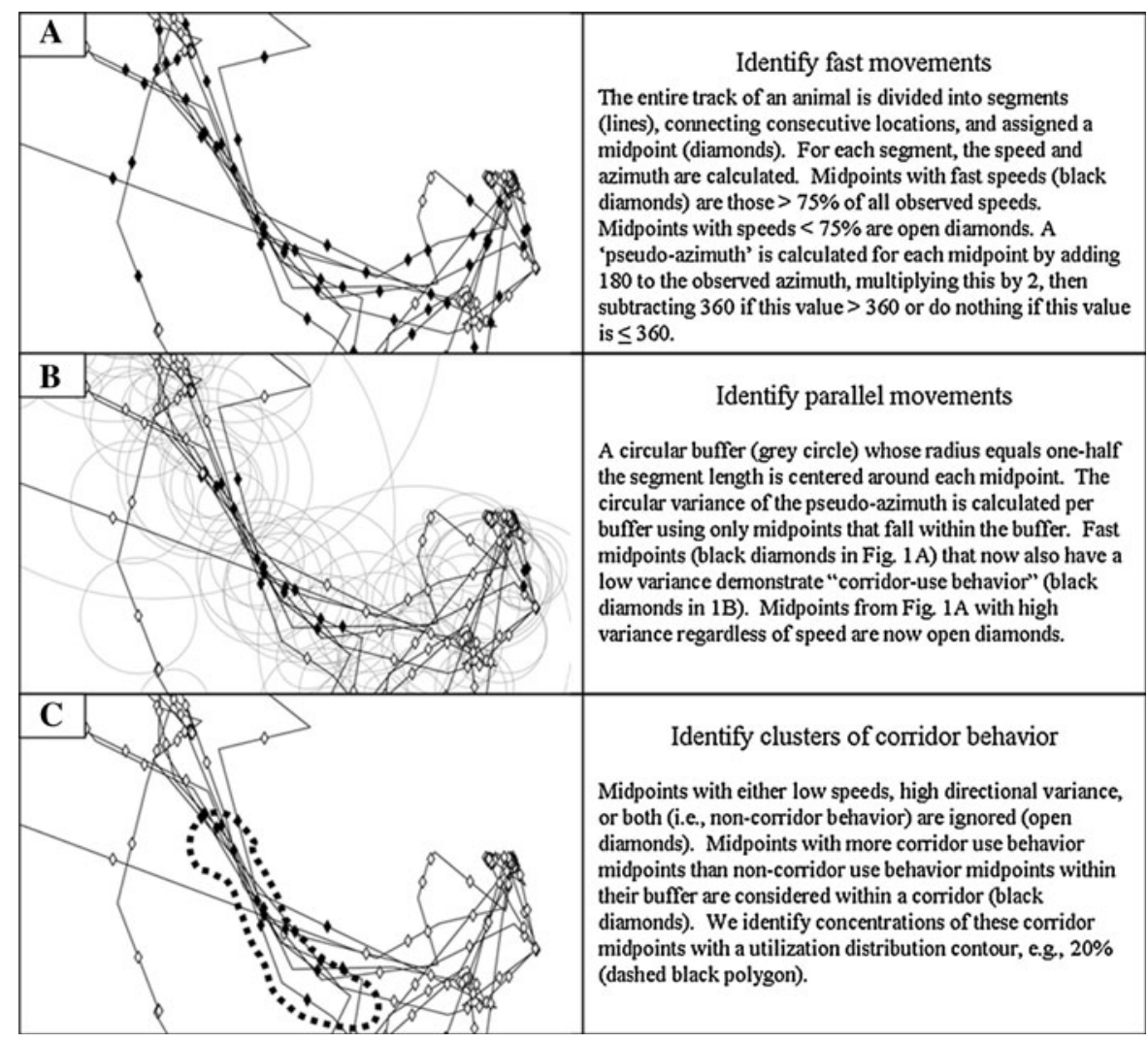


movement step length around each midpoint. We identified parallel movement steps by calculating a 'pseudo-azimuth' for each midpoint and then calculated the circular variance of these pseudo-azimuths of all midpoints falling within the buffer of each midpoint (Fig. 1b). The pseudo-azimuth is calculated for each midpoint by adding 180 to the observed azimuth, multiplying this by 2 , then subtracting 360 if this value $>360$ or do nothing if this value is $\leq 360$ (see Fig. 2). It is important to note that the pseudo-azimuth does not preserve any directional information, but rather produces a value between 0 and 360 for the circular variance calculations. After removing steps whose pseudo-azimuth circular variance was equal to 0, (indicating that no other segment midpoints occurred within the buffer radius), we identified the movement steps whose pseudo-azimuth circular variance was within the lowest percentage quartile, indicating that they are located near other parallel movement steps. Movement steps that meet both the speed and parallel requirements are considered to exhibit corridor use behavior. These conditions allowed us to remove non-corridor use behaviors such as resting and foraging that would have slower speeds and high directional variance (either from GPS fix errors or from meandering search paths) thereby focusing on corridor use as a specific behavior type. All other steps are considered non-corridor use behavior. After classifying all midpoints as being either corridor behavior or not, we searched for high concentrations of corridor behavior midpoints to identify animal-defined corridors. Considering only midpoints with at least two additional midpoints within their buffer, we classified a midpoint to be within a corridor if the majority of the midpoints within its buffer were also classified as corridor behavior. Finally, we delineated the boundaries of corridors using a contour interval (e.g., $20 \%$ ) of a fixed kernel density estimate of corridor use behavior midpoints (Fig. 1c).

\section{Corridor model validation}

We evaluated the predictions of the three corridor models (least-cost path analysis, circuit theory, and our animal-defined corridor model) by using unbaited motion-sensitive camera traps to test if corridors predicted by each model had higher mammal detection

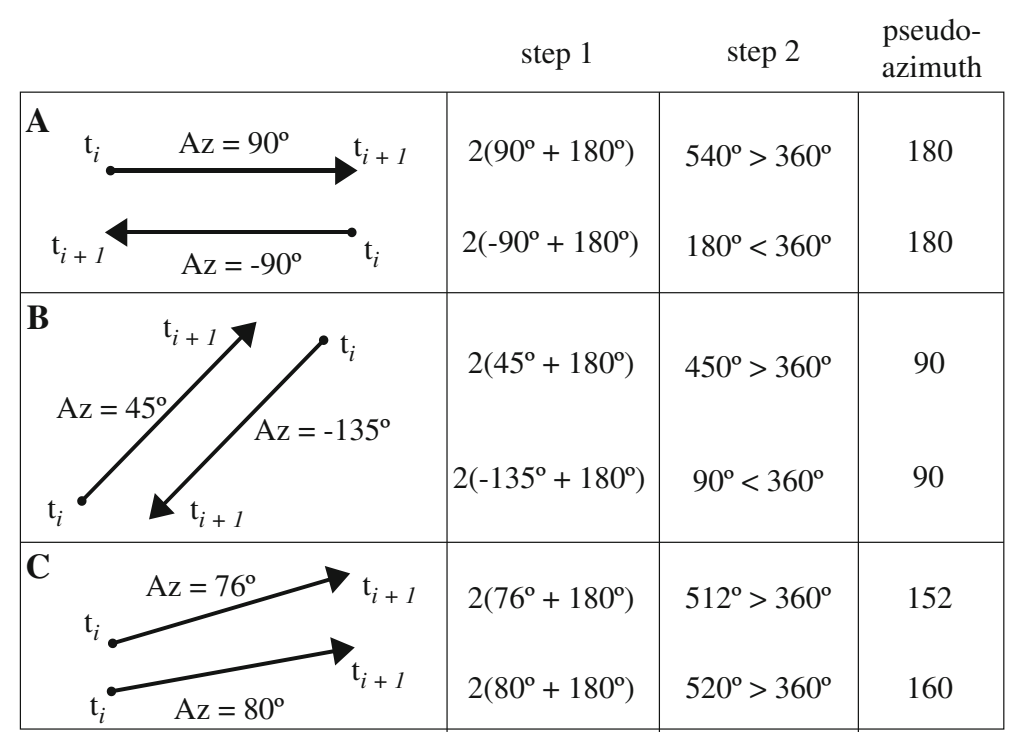

Fig. 2 Schematic for calculating a step pseudo-azimuth. The azimuth of an animals step (i.e., its direction of travel from step $t_{\mathrm{i}}$ to step $t_{\mathrm{i}+1}$ ) can have a value between $-180^{\circ} \leq 180^{\circ}$. Thus to prevent parallel steps that have opposite directions of travel from inflating the circular variance of all step azimuths within the step midpoint radius, each azimuth value is converted to a positive integer $\leq 360$. To do this we add 180 to each azimuth
("Az") and multiply this value by 2 (step 1 ). If the resulting value is $>360$, we subtract 360 , otherwise we do nothing (step 2). The final resulting value is the 'pseudo-azimuth' (step 3). Here we provide two examples of disjunct, parallel steps, but with opposite directions of travel $(A$ and $B)$ and one example of two disjunct, nearly parallel steps traveling in the same direction (C) 
Table 1 In addition to fishers, camera trap detections of mammal species were also grouped into four categories for analyses

\begin{tabular}{|c|c|c|c|c|}
\hline Species & Mammals & $\begin{array}{l}\text { Mammals excluding } \\
\text { squirrels }\end{array}$ & $\begin{array}{l}\text { Medium and large } \\
\text { mammals }\end{array}$ & Carnivores \\
\hline Didelphis virginiana & $x$ & $x$ & $\times$ & \\
\hline Canis latrans & $x$ & $x$ & $x$ & $x$ \\
\hline Vulpes vulpes & $x$ & $\times$ & $\times$ & $x$ \\
\hline Urocyon cinereoargenteus & $x$ & $\times$ & $\times$ & $x$ \\
\hline Mephitis mephitis & $x$ & $\times$ & $\times$ & $x$ \\
\hline Procyon lotor & $x$ & $x$ & $x$ & $x$ \\
\hline Martes pennanti & $x$ & $x$ & $x$ & $x$ \\
\hline Mustela erminea & $\times$ & $\times$ & $\times$ & $x$ \\
\hline Mustela frenata & $x$ & $x$ & $x$ & $x$ \\
\hline Odocoileus virginianus & $\times$ & $\times$ & $\times$ & \\
\hline Tamias striatus & $x$ & & & \\
\hline Sciurus carolinensis & $x$ & & & \\
\hline Tamiasciurus hudsonicus & $x$ & & & \\
\hline Glaucomys sp. & $x$ & & & \\
\hline Peromyscus sp. & $x$ & $x$ & & \\
\hline Sylvilagus floridanus & $x$ & $\times$ & $x$ & \\
\hline
\end{tabular}

rates than camera traps placed in nearby forest patches. We assume that cameras in true movement corridors should detect more fisher traffic than those in core areas because their narrow geometry would funnel animals near our camera. This presumes that fishers are regularly ( $\sim$ nightly) using corridors to move between forest fragments that make up their home range. If this between-fragment movement is rare, core area movement rates might be higher, but camera-based comparisons between predicted corridor areas would still be valid. Between September 2011 and January 2012 we placed a camera trap at the center of each predicted corridor location and within nearby forest patches that were used by our fishers. All cameras were spaced $>130 \mathrm{~m}$ apart, greater than the recommended minimum distance of $25 \mathrm{~m}$ (Kays et al. 2011), to avoid spatial autocorrelation of detections. Each camera (Reconyx RC55 or PC800, Holmen WI) was attached to a tree $0.5 \mathrm{~m}$ above the ground, run continuously for approximately one month, and was set to take ten pictures per trigger in rapid succession. We considered detections $>1$ min apart to be temporally independent, and analyzed movement rates for eight species groups: fishers, carnivores, carnivores excluding fishers, medium and large mammals, medium and large mammals excluding carnivores, mammals except squirrels (Sciuridae), mammals excluding carnivores and squirrels, and mammals
(Table 1). We measured the detection distance for each camera set as the maximum distance it would trigger on a human walking by, and used this to test for potential habitat-related affects on detection area. We used a general linear model (Poisson distribution, including camera deployment duration and month of deployment as offset terms) to determine whether each corridor model predicted different detection rates than expected (i.e., compared to cameras within the used forest patches).

\section{Corridor composition}

We conducted a weighted compositional analysis of habitat use (Aebischer et al. 1993; Millspaugh et al. 2006) to determine whether fisher corridors and fisher home ranges are composed of statistically different land cover types. This is the same analysis we used to estimate fisher habitat selection within their home range, except we now only used the segment midpoints identified as corridor behavior for 'use', rather than all locations, and used a dynamic Brownian bridge movement model utilization distribution of all movement step midpoints as 'available' (Kranstauber et al. 2012). For this analysis, it was necessary to combine 'use' data and 'availability' data for all individuals, by summing all corridor use behavior midpoints and all of the non-corridor use behavior 
midpoints for all of our fishers, as several fisher had insufficient corridor use behavior midpoints for the analysis. These analyses were run in program $\mathrm{R}$ (version 2.15.0; R Development Core Team 2012) using the compana function of the adehabitat package (version 0.3.5, Calenge 2006).

\section{Results}

Of the 12 fishers captured and tagged, four had to be excluded from analysis (one male dispersed, one female denned during her tag deployment, and two males removed their collars early during their deployment). The remaining eight tags (5 males, 3 females) recorded for a combined 242 days (means of 38 and 18 days, males and females, respectively), during winter (mid-December-end of March) producing 31,985 GPS fixes (means of 5,226 and 1,951 per male and female, respectively, see Fig. 3 for an example). Tracking data for these animals are available at Movebank.org (DOI: 10.5441/001/1.2tp2j43g).

A total of $5 \%$ of fisher movements met our criteria to be considered potential corridor use behavior, and $18 \%$ of these were concentrated into 23 animaldefined corridors. Based on our criteria, one female and one male did not exhibit corridor use, whereas the remaining six fishers repeatedly used between 2 and 7 corridors within their home ranges. This female used a very small home range $\left(1.1 \mathrm{~km}^{2}\right)$ and did not require multiple forest fragments, and the male lived in an area of continuous forest, (i.e., a single, large habitat patch). We excluded these two fishers from the corridor validation tests and the corridor composition analysis as they did not demonstrate corridor use, thus we could not validate the animal-defined corridor model predictions nor could we quantify their corridor compositions.

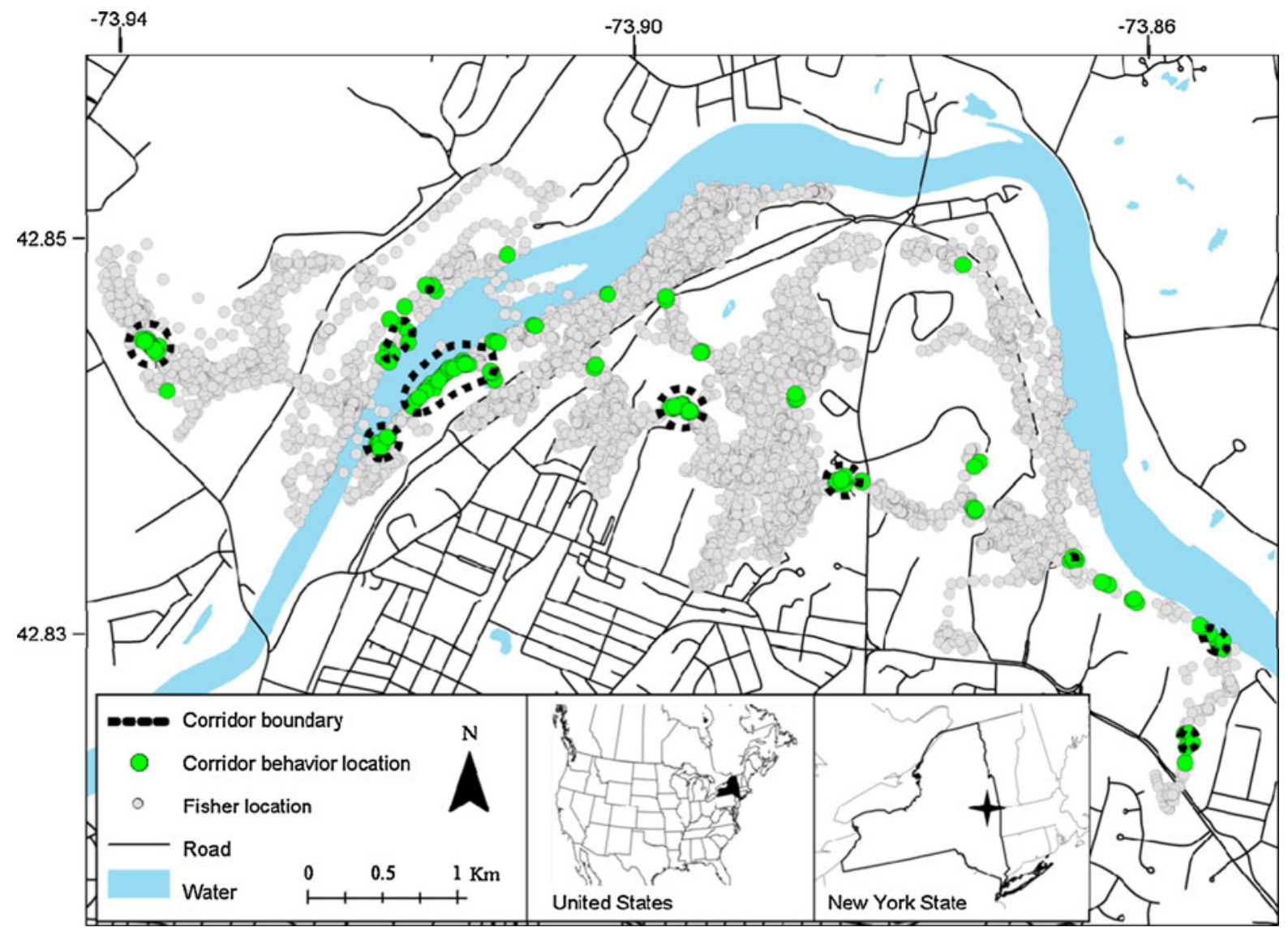

Fig. 3 Map highlighting the results of the animal-defined corridor model for one urban male fisher. Corridor boundaries are delineated with a $20 \%$ isopleth (dashed) of a utilization distribution as an example 
The weighted compositional analysis produced standardized pairwise log-ratio difference values between -14.9 and 8.35 (Table 2). We translated these values into 'cost' (i.e., land cover resistance) values per individual, that varied for the same land cover type across individuals (Table 2). Using these values, least-cost path analysis identified 17 potential corridors (1-6, per individual) and circuit theory identified 28 corridors (1-7, per individual) within the home ranges of these animals (see Fig. 4 for examples). Of the 23 animal-defined corridors, only one was predicted by least-cost path analysis and only five were predicted by circuit theory. Only six of the 17 and 28 corridors predicted by least-cost path analysis and circuit theory, respectively, overlapped.

To test whether predicted corridors received higher mammal traffic than forest patches, we deployed camera traps for a total of 1,909 trap nights. We were able to monitor 24 forest patch locations, but flooding, restricted access to private property, and infeasibility of some suggested corridor sites (e.g., car parking lot) limited our corridor monitoring to 40 of the 55 predicted corridor locations. Five of the monitored corridors were identified by two different corridor models and two were identified by all three corridor models, thus a single camera trap at these sites simultaneously recorded detections for multiple corridor models. The camera detection distance to a human ranged from 3.2 to $19.1 \mathrm{~m}($ mean $=10.3 \mathrm{~m})$ and did not vary significantly with location type (ANOVA; $F$ value $=0.368, P=0.78$ ). Detection rates were spatially independent for each species grouping (Moran's I; $P>0.25$ ). Detections of species groups, except fishers, were significantly negatively affected by the camera deployment month, with early (i.e., autumn) deployments having higher detection rates than later deployments (general linear model, $t$ values $<-2.182, P<0.05)$. For fisher detections we ran two general linear models, one with the camera deployment month as an offset and one without, but ultimately chose the more robust model for interpretation as it produced a lower AIC value.

Compared to cameras placed within forest patches, cameras within our animal-defined corridors detected higher numbers of each of our species groupings $(P<0.05)$ (Table 3$)$. Detection rates for circuit theory cameras were significantly higher for most nont-target mammal groups $(P<0.001)$, but were lower for fishers and carnivores (Table 3). Least-cost path cameras detected significantly higher rates for mammals $(P<0.001)$, but also significantly lower detection rates for mammals excluding squirrels and medium and large mammals (Table 3). Fisher detections were $64 \%$ higher at cameras within least-cost path corridors than in nearby forest patches, but this improvement was not statistically significant $(P=0.655)$, probably due to the low number of least-cost path corridors $(n=6)$ that we were able to monitor and the overall low number of detections of fishers $(n=39$, five of which were detected within least-cost path corridors. A post hoc power test with unequal observations, using an alpha of 0.05 , suggests we needed to monitor three more least-cost path corridors in order to detect our observed effect size of 1.643).

Fisher corridors have a different land cover type composition than their home ranges (Fig. 5). Our animal-defined corridor model suggested fisher corridors are composed of a variety (15 of 22) of the land cover types included in our analyses, with forested wetlands and deciduous forests being most prominent (Fig. 5). Fisher corridors contained more forested wetlands, deciduous forests, pastures, and more 5 and 35 mile per hour roads than would be expected based on the typical fisher home range composition. Of the five most prominent corridor land cover types, only two were forests, with the remaining three being cropland, developed open space (e.g., golf course or cemetery) and pastures (Fig. 5). In contrast, all of the 22 land cover types were found in fisher home ranges, and four of the five most prominent home range land cover types were forests: deciduous forest, mixed forest, coniferous forest, pasture, and forested wetland, in decreasing order of selection (Fig. 5).

\section{Discussion}

Corridors are widely viewed as important tools for maintaining landscape connectivity (Gilbert-Norton et al. 2010), yet there has been little empirical evidence to test whether mammals actually move through predicted corridors. Our high-resolution tracking data show that fishers use movement corridors to connect fragmented habitats within their home ranges. The two fishers that did not show corridor-like movement behavior were also not observed moving between forest fragments, maintaining home ranges 


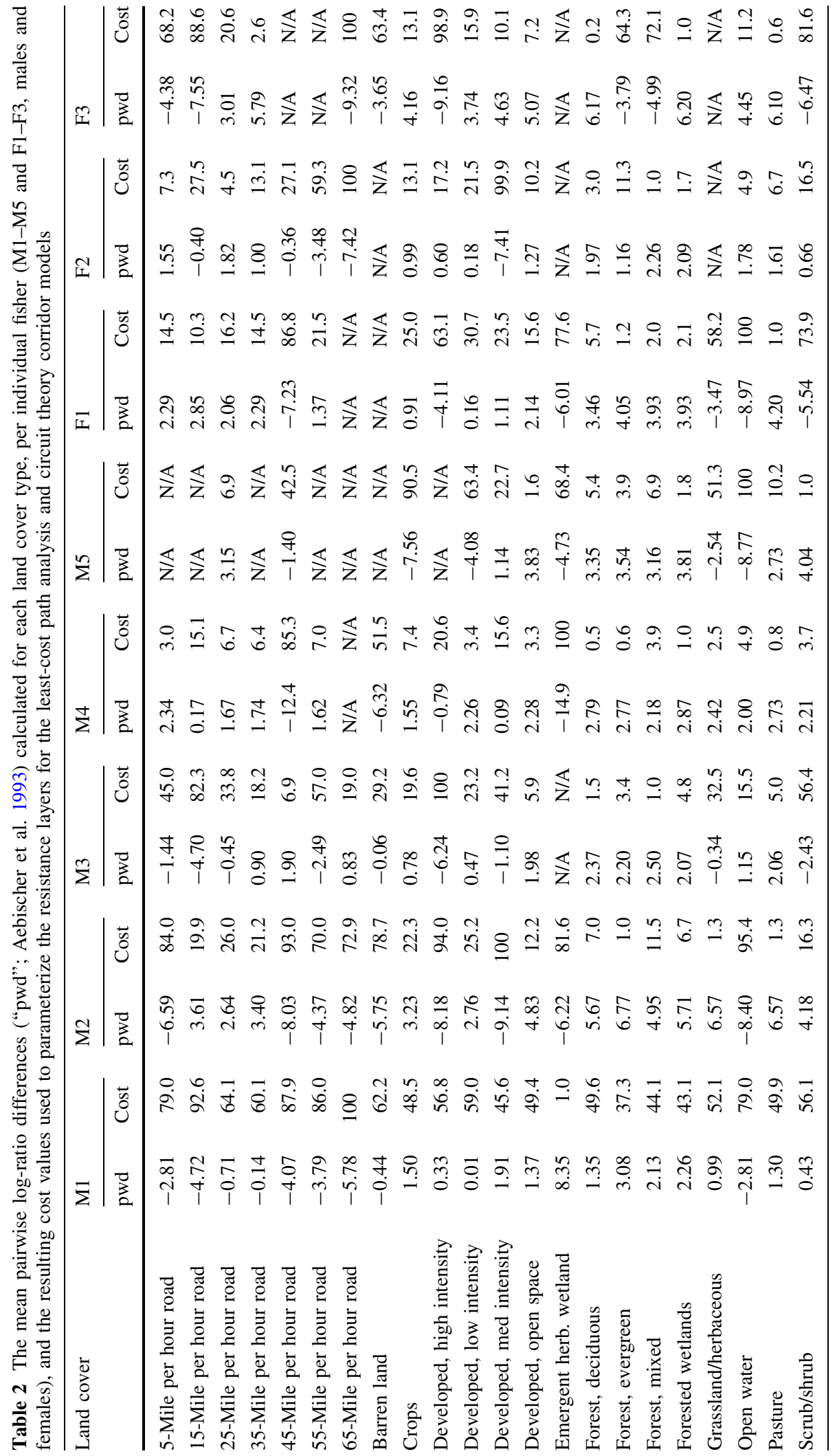


Fig. 4 Maps of the home range landscape, animaldefined corridors,

Circuitscape output, and least-cost paths of two male fishers. Our animal-defined corridor model suggests that the fisher within the fragmented landscape (right column) demonstrated corridor use (indicated with utilization contours around high densities of corridor behavior locations, red polygons) while the fisher within the continuous landscape (left column) did not (indicated by the lack of corridor behavior location clusters). For the fisher with no observed corridor use, both Circuitscape (red to green labeling suggests low to high flow) and least-cost path analysis (connected blue cells) still predicted corridor locations between rest sites (green stars). Both Circuitscape and least-cost path analysis did predict two of the five observed corridors for the fisher in the fragmented landscape (indicated)

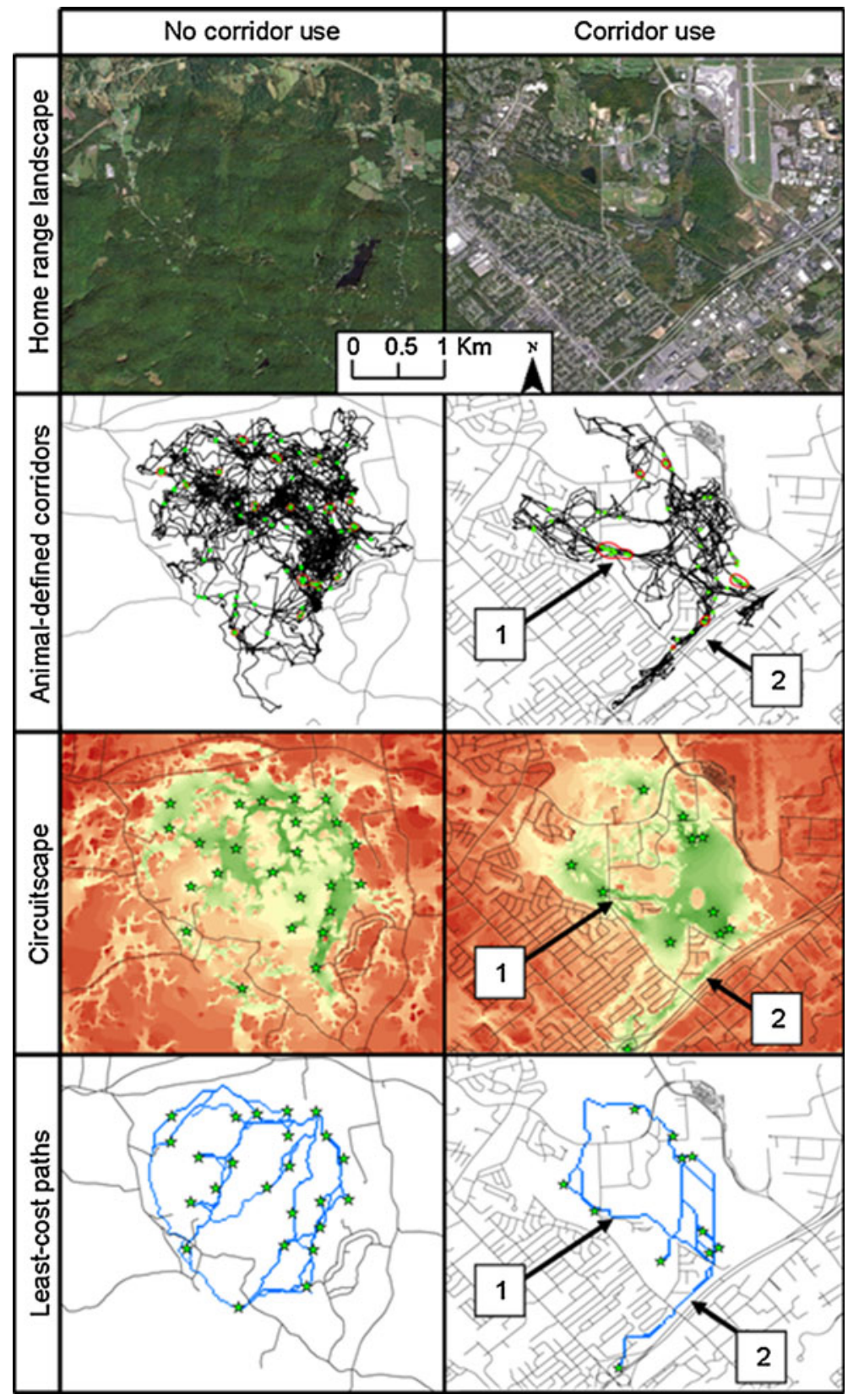

that were nearly uniformly forested with no anthropogenic barriers. This suggests that corridor use may be a behavioral adaptation by fishers to fragmented landscapes. Furthermore, using fishers as a model species, we demonstrated a repeatable approach to wildlife corridor identification that uses field data and emphasizes animal behavior, while reducing assumptions inherent to cost-based corridor models. Unfortunately, the corridors used by our study animals were generally not well predicted by the cost-based corridor models, emphasizing the need for further integration of animal behavior data into corridor models and for validating corridor model predictions with independent field data (Chetkiewicz et al. 2006; Beier et al. 2008; Sawyer et al. 2011).

Cost-based corridor models are sensitive to numerous factors including the anthropocentric categorizations of landscape variables fed into the model, their 
Table 3 Mean detection rates (detections/day) and mammal species richness for camera traps deployed in forest patches and corridors predicted by the three different models, with sample sizes in parentheses

\begin{tabular}{|c|c|c|c|c|}
\hline Species groupings & $\begin{array}{l}\text { Forest patch } \\
(24)\end{array}$ & $\begin{array}{l}\text { Animal-defined } \\
\text { corridors }(17)\end{array}$ & $\begin{array}{l}\text { Circuit theory } \\
\text { corridors (17) }\end{array}$ & $\begin{array}{l}\text { Least-cost path } \\
\text { corridors }(6)\end{array}$ \\
\hline Fishers (39) & 0.018 & $0.031^{\mathrm{a}}$ & 0.012 & 0.028 \\
\hline Carnivores (271) & 0.139 & $0.185^{\mathrm{b}}$ & 0.094 & 0.122 \\
\hline Carnivores excluding fishers (232) & 0.121 & $0.154^{\mathrm{b}}$ & 0.082 & 0.094 \\
\hline Medium and large mammals $(1,054)$ & 0.475 & $0.587^{\mathrm{b}}$ & $0.622^{\mathrm{b}}$ & $0.431^{\mathrm{c}}$ \\
\hline $\begin{array}{l}\text { Medium and large mammals excluding } \\
\text { carnivores (783) }\end{array}$ & 0.336 & $0.403^{b}$ & $0.528^{\mathrm{b}}$ & $0.310^{\mathrm{a}}$ \\
\hline Mammals excluding squirrels $(1,193)$ & 0.525 & $0.697^{\mathrm{b}}$ & $0.696^{\mathrm{b}}$ & $0.462^{\mathrm{c}}$ \\
\hline $\begin{array}{l}\text { Mammals excluding squirrels and } \\
\text { carnivores (922) }\end{array}$ & 0.387 & $0.512^{\mathrm{b}}$ & $0.602^{\mathrm{b}}$ & $0.341^{\mathrm{a}}$ \\
\hline Mammals $(2,343)$ & 0.776 & $1.379^{\mathrm{b}}$ & $1.327^{\mathrm{b}}$ & $1.857^{\mathrm{b}}$ \\
\hline Mammal species richness (16) & 12 & 15 & 13 & 10 \\
\hline
\end{tabular}

Superscripts indicate significance levels $\left({ }^{\mathrm{a}} P<0.05,{ }^{\mathrm{b}} P<0.01,{ }^{\mathrm{c}} P<0.001\right)$ for results from a general linear model comparing detection rates for each corridor model to nearby forest patches

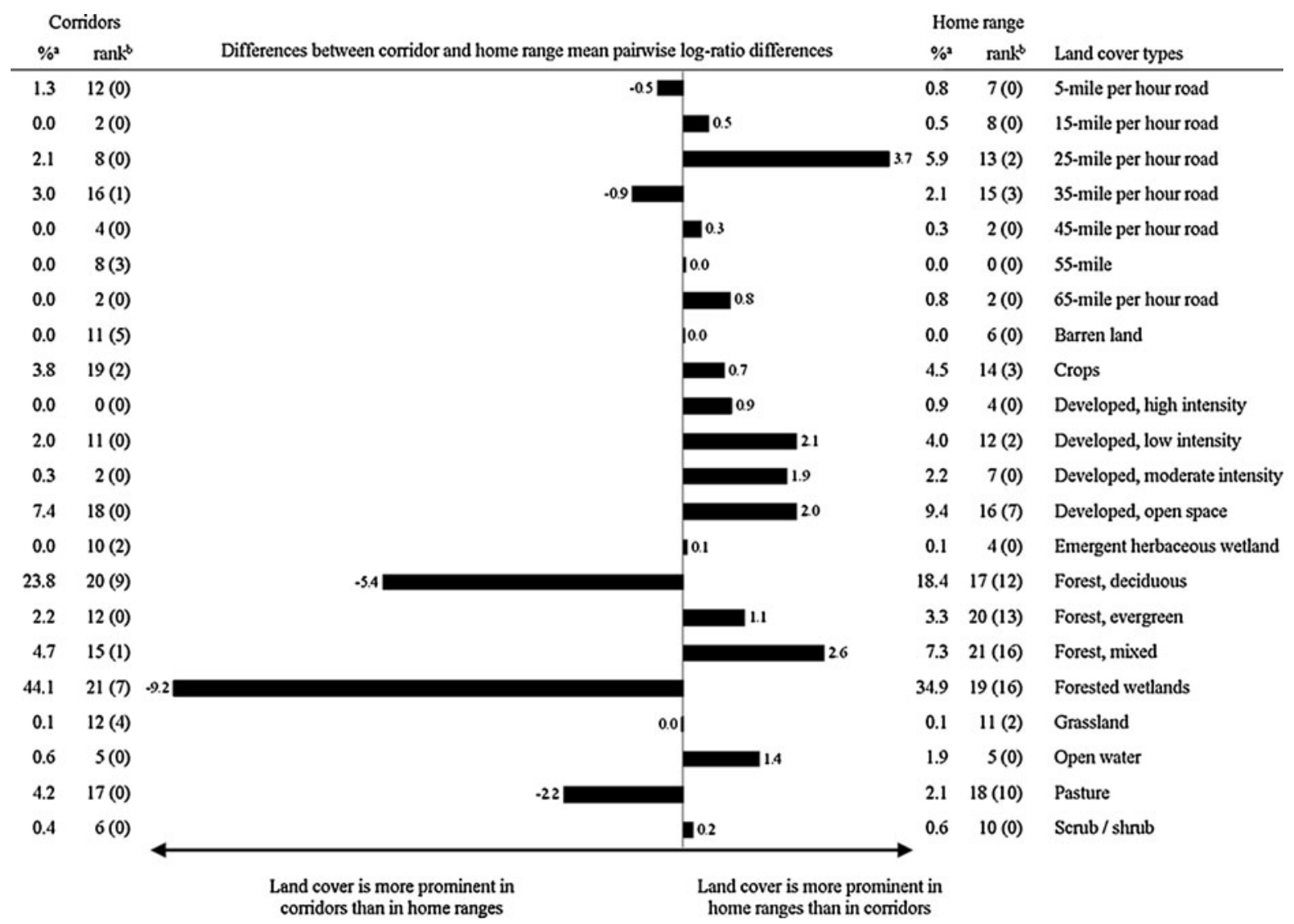

Fig. 5 Land cover composition of corridors and home ranges of urban fishers demonstrating corridor use (6 of the 8 fishers studied). Horizontal bars indicate whether land cover types were more prominent within animal-defined corridors (to the left of the $Y$-axis) or within fisher home ranges (to the right of the $Y$-axis), based on the difference between the mean log-ratio pairwise differences (Aebischer et al. 1993) per land cover type for corridors and home ranges 
resistance estimates, and both the spatial and temporal grain and scale of the landscape under study (Rayfield et al. 2010; Sawyer et al. 2011). Our use of tracking data to calculate land cover resistance values for these models is the recommended best practice (Beier et al. 2008; Chetkiewicz and Boyce 2009; Sawyer et al. 2011). Despite this, circuit theory predicted only $22 \%$ (5 of 23) and least-cost path analysis predicted only $4 \%$ ( 1 of 23 ) of the corridors actually used by our study animals, and further, our camera detection data suggest that locations that our interpretation of circuit theory current maps suggested were corridors received less fisher traffic than cameras within forest patches. Because of our decision to model cost-based corridors between rest sites, a few of their predicted corridors were located within a continuous forest patch. This may have reduced their camera detection rates, but this does not detract from their inability to predict the corridors used by our study animals. We believe that these differences are real and are not related to our decision to model cost-based corridors between fisher rest sites rather than between habitat cores, patches, or home range boundaries. Since fisher rest sites were numerous and located throughout the forest patches within a fisher's home range, and because the costbased corridors are forced between all combinations of these rest sites, the cost-based corridor models should predict corridors between these forest patches, without the need for subjective boundary delineations.

We believe that the little overlap between the costbased predictions and observed fisher corridors is due to differences between fisher's land cover selection for corridors in comparison with their home ranges (Fig. 5), which we used to build our resistance layers for cost-based models (Sawyer et al. 2011; Zeller et al. 2012). For example, four of the five most preferred (i.e., highest ranking) fisher home range land cover types were forests, whereas only two of the five most preferred corridor land cover types were forests. The relative cost values assigned to the landscape variables and the spatial arrangement of these cost values are known to influence the results of cost-based resistance mapping (Rayfield et al. 2010). We would not suggest that corridors designed for fishers should be composed of land cover types other than those that they prefer (i.e., forests). Rather, our results suggest that corridor planners should not immediately discount these suboptimal land cover types if they are in connecting areas, and should recognize that fishers, and possibly other species, are able to utilize suboptimal cover types to connect more desirable areas. Finding that fishers select for forests is not surprising (Powell 1993; Lofroth et al. 2011). Yet, although fishers prefer forests, our data suggest that connecting separate habitat fragments is so important for suburban fishers that they are willing to use corridors composed of sub-optimal land cover types (e.g., crops, open space, and pastures). Our field observations (snow tracking and ad-hoc camera traps) also suggest that fishers made regular use of under-road tunnels and drainage pipes to cross beneath roads, including one individual who repeatedly crossed beneath a 6-lane, heavily traveled highway. Both their use of these under-road tunnels and their corridor land cover composition offer important insight into this species perception of landscape connectivity (Lima and Zollner 1996), their ability to cross gaps in forest cover (Dale et al. 1994), and have significant implications for fisher corridor modeling.

We believe unbaited camera traps provided a good test for within home-range movement corridors, where resident mammals should pass through movement corridors regularly. Camera traps are increasingly popular in ecology and conservation and have been used previously to monitor fishers (Kays and Slauson 2008), yet to our knowledge this work is the first to use cameras to validate corridor model predictions. We urge researchers to consider the type and frequency of expected corridor use when designing corridor monitoring studies, including an awareness of seasonal biases in detections rates that may be attributed to increased activity, such as the high camera detection rate we observed for of sciurids preparing for winter. For example, dispersal is vitally important for biodiversity, yet confirming dispersal via corridors remains a challenge, as dispersers are less likely to pass the same camera multiple times, thus reducing their detection rates and making it difficult to distinguish them from random probability. Molecular data provide useful insight into landscape connectivity, but is best suited for measuring historic landscape connectivity (Schwartz et al. 2009) and should be used as complimentary data, particularly as recent landscape changes may require decades to be detected via population genetic methods (Spear et al. 2010).

Carefully selecting a species as a model for other local species could be a feasible alternative to more challenging multi-species corridor approaches, provided the corridor model predictions are validated 
with field data. Our camera trap detection data suggest that the predicted animal-defined corridors received higher traffic rates of fishers and each of the other nontarget mammal species groups that we considered, suggesting that fishers are a suitable model species for the other forest dependent mammal species within our study area. Unfortunately however, this can not be said for the cost-based corridor models tested here. It appears that circuit theory failed to predict corridors for fishers and carnivores in general and least-cost path analysis predicted more fisher traffic, but less of each of the non-target species groups except sciurids. These shortcomings may limit their utility for multi-species corridor planning. We believe that these shortcomings can be overcome by further integrating animal behavior into corridor models and recognizing corridor use as a behavior, as with our animal-defined corridor model, rather than estimating movement resistance from habitat preference information. It is interesting to note however that each of the corridor models predicted high sciurid traffic. This may not be related to the corridor models themselves, but rather due to the sciurids increased activity during our sampling season or because predicted corridors often passed through residential areas where $S$. carolinensis (the most commonly detected species) in particular may be especially active collecting supplemental food from backyard bird feeders.

Our animal-defined corridor model was effective in identifying fisher corridors, yet it is not without its limitations. First, our model requires the capturing and monitoring or free-ranging animals, which may prove difficult for rare and/or elusive species, yet we believe that the additional information garnered from this effort (e.g., home range estimates, activity patterns, habitat selection, etc.) outweigh the required additional effort. Another shortcoming of our method is that it applies to within home range corridors and thus cannot directly predict corridors at larger scales. However, our method does objectively identify movement corridors, allowing users to avoid many of the assumptions and shortcomings of cost-based corridor models, such as potential landscape variable layer inaccuracies, proper landscape resistance parameterizations, and reduces assumptions of animal knowledge of the target landscape. Further, our results highlight the potential for animal behavior data to improve cost-based corridor models, and the need to do so. Our corridor model results can be re-incorporated into the landscape resistance estimates required for cost-based corridor modeling, thereby producing a more realistic estimate of landscape resistance to animal corridor use, rather than resistance to animal habitat selection. Finally, our animal-defined corridor model can be applied across many species and landscapes, even immediately applied to existing animal movement datasets (e.g., www.movebank.org).

Maintaining animal movements through dynamic and challenging landscapes is crucial for biodiversity (Bennett 2003; Nathan et al. 2009). Our paper confirms that animals will move through corridors to connect fragmented habitat patches, supporting their value for conservation. We also offer two field tests of corridor model predictions: active animal tracking and passive monitoring with remote cameras. Our results suggest that cost-based models may be inaccurate if they ignore unique interactions between animal behaviors and particular landscape features. Although we are enthusiastic about the potential for corridor modeling to inform conservation decisions, we agree with Chetkiewicz et al. (2006) that more progress is needed to incorporate independent data into these models to make them more accurate and useful.

Acknowledgments This work was supported in part by NSF (Grant 0756920 to RK), the New York State Museum, the MaxPlanck-Institute for Ornithology, the North Carolina Museum of Natural Sciences, and the National Geographic Society Waitt Grant Program (Grant W157-11 to SL). We thank the Albany Pine Bush Preserve, Joseph Bopp, Joseph Chase, Neil Gifford, Wolfgang Heidrich, Bar Kranstauber, Franz Kümmeth, Kevin McLean, Tristan Nuňez, Lisa Pipino, Roger Powell, Kamran Safi, Marco Smolla, and Brad Stratton for their support and valuable input. This manuscript benefited from comments from C. Vos and two anonymous reviewers.

Open Access This article is distributed under the terms of the Creative Commons Attribution License which permits any use, distribution, and reproduction in any medium, provided the original author(s) and the source are credited.

\section{References}

Adriaensen F, Chardon JP, De Blust G, Swinnen E, Villalba S, Gulinck H, Matthysen E (2003) The application of 'leastcost' modeling as a functional landscape model. Landsc Urban Plan 64:233-247

Aebischer NJ, Robertson P, Kenward RE (1993) Compositional analysis of habitat use from animal radio-tracking data. Ecology 74:1313-1325

Bartoń KA, Hovestadt T, Phillips BL, Travis JMJ (2012) Risky movement increases the rate of range expansion. Proc $\mathrm{R}$ Soc B Biol Sci 279:1194-1202 
Beier P, Majka DR, Spencer WD (2008) Forks in the road: choices in procedures for designing wildland linkages. Conserv Biol 22:836-851

Bennett AF (2003) Linkages in the landscape: the role of corridors and connectivity in wildlife conservation, 2 nd edn. IUCN, Gland

Brown JH, Kodric-Brown A (1977) Turnover rates in insular biogeography: effect of immigration on extinction. Ecology 58:445-449

Brown DD, LaPoint S, Kays R, Heidrich W, Kümmeth F, Wikelski M (2012) Accelerometer-informed GPS telemetry: reducing the trade-off between resolution and longevity. Wildl Soc B 36:139-146

Buchmann CM, Schurr FM, Nathan R, Jeltsch F (2012) Movement upscaled - the importance of individual foraging movement for community response to habitat loss. Ecography 35:436-445

Calenge $C$ (2006) The package adehabitat for the R software: a tool for the analysis of space and habitat use by animals. Ecol Model 197:516-519

Chetkiewicz C-LB, Boyce MS (2009) Use of resource selection functions to identify conservation corridors. J Appl Ecol 46:1036-1047

Chetkiewicz C-LB, St. Clair CC, Boyce MS (2006) Corridors for conservation: integrating pattern and process. Annu Rev Ecol Evol Syst 37:317-342

Cumming GS, Cornélis D (2012) Quantitative comparison and selection of home range metrics for telemetry data. Divers Distrib 18:1057-1065

Dale VH, Pearson SM, Offerman HL, O’Neill RV (1994) Relating patterns of land-use change to faunal biodiversity in the Central Amazon. Conserv Biol 8:1027-1036

Driezen K, Adriaensen F, Rondini C, Doncaster CP, Matthysen E (2007) Evaluating least-cost model predictions with empirical dispersal data: a case-study using radiotracking data of hedgehogs (Erinaceus europaeus). Ecol Model 209:314-322

ESRI (2008) Spatial Analyst toolbox for ArcGIS Desktop version 9.3. Environmental Systems Research Institute, Redlands, CA.

Fahrig L (2007) Non-optimal animal movement in humanaltered landscapes. Funct Ecol 21:1003-1015

Fauchald P, Tverra T (2003) Using first-passage time in the analysis of area-restricted search and habitat selection. Ecology 84:282-288

Forman RTT (1995) Land mosaics: the ecology of landscapes and regions. Cambridge University Press, New York

Forman RTT, Sperling D, Bissonette JA, Clevenger AP, Cutshall CD, Dale VH, Fahrig L, France R, Goldman CR, Heanue K, Jones JA, Swanson FJ, Turrentine T, Winter TC (2003) Road ecology: science and solutions. Island Press, Washington, DC

Fry J, Xian G, Jin S, Dewitz J, Homer C, Yang L, Barnes C, Herold N, Wickham J (2011) Completion of the 2006 National Land Cover Database for the Conterminous United States. Photogramm Eng Remote Sens 77:858-864

Gilbert-Norton L, Wilson R, Stevens JR, Beard KH (2010) A meta-analytic review of corridor effectiveness. Conserv Biol 24:660-668

Gurarie E, Andrews RD, Laidre KL (2009) A novel method for identifying behavioural changes in animal movement data. Ecol Lett 12:395-408
Haas CA (1995) Dispersal and use of corridors by birds in wooded patches on an agricultural landscape. Conserv Biol 9:845-854

Hilty JA, Lidicker WZ, Merenlender AM (2006) Corridor ecology: the science and practice of linking landscapes for biodiversity conservation. Island Press, Washington, DC

Hobbs RJ (1992) The role of corridors in conservation: solution or bandwagon? Trends Ecol Evol 7:389-392

Hodgson JA, Thomas CD, Wintle BA, Moilanen A (2009) Climate change, connectivity, and conservation decision making: back to basics. J Appl Ecol 46:964-969

Huck M, Jędrzejewski W, Borowik T, Jędrzejewska B, Nowak S, Myslajek RW (2011) Analyses of least cost paths for determining effects of habitat types on landscape permeability: wolves in Poland. Acta Theriol 56:91-101

Johnson DH (1980) The comparison of usage and availability measurements for evaluating resource preference. Ecology 61:65-71

Jonsen ID, Flemming JM, Myers RA (2005) Robust state-space modeling of animal movement data. Ecology 86:28742880

Kays RW, Slauson KM (2008) Remote cameras. In: Long RA, MacKay P, Zielinski WJ, Ray JC (eds) Noninvasive methods for surveying carnivores. Island Press, London, pp 105-134

Kays R, Tilak S, Kranstauber B, Jansen PA, Carbone C, Rowcliffe M, Fountain T, Eggert J, He Z (2011) Camera traps as sensor networks for monitoring animal communities. Int J Res Rev Wirel Sens Netw 1:19-29

Kilpatrick HJ, Rego PW (1994) Influence of season, sex, and site availability on fisher (Martes pennanti) rest-site selection in the central hardwood forest. Can J Zool 72: 1416-1419

Kranstauber B, Smolla M (2013) Move: visualizing and analyzing animal track data. http://CRAN.R-project.org/ package $=$ move

Kranstauber B, Kays R, LaPoint SD, Wikelski M, Safi K (2012) A dynamic Brownian bridge movement model to estimate utilization distributions for heterogeneous animal movement. J Appl Ecol 81:738-746

LaRue MA, Nielsen CK (2008) Modelling potential dispersal corridors for cougars in midwestern North America using least-cost path methods. Ecol Model 212:372-381

Lewis JC, Powell RA, Zielinski WJ (2012) Carnivore translocations and conservation: insights from population models and field data for fishers (Martes pennanti). PLoS One 7:e32726

Li H, Li D, Li T, Qiao Q, Yang J, Zhang H (2010) Application of least-cost path model to identify a giant panda dispersal corridor network after the Wenchuan earthquake-Case study of Wolong Nature Reserve in China. Ecol Model 221:944-952

Lima SL, Zollner PA (1996) Towards a behavioral ecology of ecological landscapes. Trends Ecol Evol 11:131-135

Lofroth EC, Raley CM, Higley JM, Truex RL, Yaeger JS, Lewis JC, Happe PJ, Finley LL, Naney RH, Hale LJ, Krause AL, Livingston SA, Myers AM, Brown RN (2011) Conservation of fishers (Martes pennanti) in South-Central British Columbia, Western Washington, Western Oregon, and California: Volume I: Conservation Assessment. USDI Bureau of Land Management, Denver 
McRae BH, Dickson BG, Keitt TH, Shah VB (2008) Using circuit theory to model connectivity in ecology, evolution, and conservation. Ecology 89:2712-2724

Mech SG, Hallett JG (2001) Evaluating the effectiveness of corridors: a genetic approach. Conserv Biol 15:467-474

Millspaugh JJ, Nielson RM, McDonald L, Marzluff JM, Gitzen RA, Rittenhouse CD, Hubbard MW, Sheriff SL (2006) Analysis of resource selection using utilization distributions. J Wildl Manage 70:384-395

Morales JM, Haydon DT, Frair J, Holsinger KE, Fryxell JM (2004) Extracting more our of relocation data: building movement models as mixtures of random walks. Ecology 85:2436-2445

Morales JM, Moorcroft PR, Matthiopoulos J, Frair JL, Kie JG, Powell RA, Merrill EH, Haydon DT (2010) Building the bridge between animal movement and population dynamics. Philos Trans R Soc B 365:2289-2301

Nathan R, Getz WM, Revilla E, Holyoak M, Kadmon R, Saltz D, Smouse PE (2009) A movement ecology paradigm for unifying organismal movement research. Proc Natl Acad Sci USA 105:19052-19059

Nathan R, Spiegel O, Fortmann-Roe S, Harel R, Wikelski M, Getz WM (2012) Using tri-axial acceleration data to identify behavioral modes of free-ranging animals: general concepts and tools illustrated for griffon vultures. J Exp Biol 215:986-996

New York State Office of Cyber Security (2006) New York State Streets. Available for download at: http://gis.ny.gov/ gisdata/inventories/details.cfm?DSID $=932$

Poor EE, Loucks C, Jakes A, Urban DL (2012) Comparing habitat suitability and connectivity modeling methods for conserving pronghorn migrations. PLoS One 7:e49390

Powell RA (1993) The fisher: life history, ecology, and behavior. University Minnesota Press, Minneapolis

Powell RA (1994) Effects of scale on habitat selection and foraging behavior of fishers in winter. J Mammal 75: 349-356

R Development Core Team (2012) R: a language and environment for statistical computing. R Foundation for Statistical Computing, Vienna

Rayfield B, Fortin M-J, Fall A (2010) The sensitivity of leastcost habitat graphs to relative cost surface values. Land Ecol 25:519-532
Rosenberg DK, Noon BR, Meslow EC (1997) Biological corridors: form, function, and efficacy. Bioscience 47:677687

Rudnick DA, Ryan SJ, Beier P, Cushman SA, Dieffenbach F, Epps CW, Gerber LR, Hartter J, Jenness JS, Kintsch J, Merenlender AM, Perkl RM, Preziosi DV, Trombulak SC (2012) The role of landscape connectivity in planning and implementing conservation and restoration priorities. Issues Ecol 16:1-20

Sawyer SC, Epps CW, Brashares JS (2011) Placing linkages among fragmented habitats: do least-cost models reflect how animals use landscapes? J Appl Ecol 48:668-678

Schwartz MK, Copeland JP, Anderson NJ, Squires JR, Inman RM, McKelvey KS, Pilgrim KL, Waitts LP, Cushman SA (2009) Wolverine gene flow across a narrow climatic niche. Ecology 90:3222-3232

Simberloff D, Farr JA, Cox J, Mehlman DW (1992) Movement corridors: conservation bargains or poor investments? Conserv Biol 6:493-504

Simpson GG (1940) Mammals and land bridges. J Wash Acad Sci 30:137-163

Smouse PE, Focardi S, Moorcroft PR, Kie JG, Forester JD, Morales JM (2010) Stochastic modeling of animal movement. Philos Trans R Soc B 365:2201-2211

Spear SF, Balkenhol N, Fortin M-J, McRae BH, Scribner K (2010) Use of resistance surfaces for landscape generic studies: considerations for parameterization and analysis. Mol Ecol 19:3576-3591

United States Census (2008) American Fact Finder. Accessed March 2012

Walpole AA, Bowman J, Murray DL, Wilson PJ (2012) Functional connectivity of lynx at their southern range periphery in Ontario, Canada. Land Ecol 27:761-773

Wikelski M, Kays R (2012) Movebank: archive, analysis and sharing of animal movement data. World Wide Web electronic publication. http://www.movebank.org

Wikelski M, Kays RW, Kasdin NJ, Thorup K, Smith JA, Swenson GW (2007) Going wild: what a global smallanimal tracking system could do for experimental biologists. J Exp Biol 210:181-186

Zeller KA, McGarigal K, Whiteley AR (2012) Estimating landscape resistance to movement: a review. Landscape Ecol 27:777-797 